\title{
"PROJETO APRENDIZ": INTERAÇÃO UNIVERSIDADE-ESCOLA PARA REALIZAÇÃO DE ATIVIDADES EXPERIMENTAIS NO ENSINO MÉDIO
}

\section{The "Apprentice Project": interaction university-school to realize experimental activities in the High School}

\author{
Raphael Alves Feitosa ${ }^{1}$ \\ Raquel Crosara Maia Leite ${ }^{2}$ \\ Ana Lúcia Ponte Freitas ${ }^{3}$
}

\begin{abstract}
Resumo: O Projeto "Aprendiz" é uma iniciativa do Programa de Educação Tutorial da Biologia da UFC, cuja ação de destaque é o incentivo à reativação de laboratórios de aulas práticas de ciências em escolas públicas de Fortaleza. O objetivo desta pesquisa é investigar as expectativas e dificuldades dos docentes para a implantação de atividades experimentais, durante a aplicação do "Projeto Aprendiz", bem como a superação destes obstáculos. Buscamos desvelar o potencial que a interação universidade/escola pública, professores e licenciandos possui para a formação de docentes de Ciências e Biologia. Apesar das diversas dificuldades, o trabalho conjunto de professores em exercício e futuros docentes trouxe contribuição para a formação de ambos. Com a pesquisa, professores, licenciandos e pesquisadores tiveram a possibilidade de expressar suas concepções e refletir sobre a realização de atividades práticas nas escolas públicas.
\end{abstract}

Palavras-chave: Atividades experimentais. Formação de professores. Ensino de Ciências.

\begin{abstract}
The "Apprentice Project" is an initiative of the Ceará Federal University (UFC) for Tutorial Biology Education, which focus on promoting incentives to reactivate science practice lab classes in public schools in the city of Fortaleza, Brazil. The objective of this research is to investigate the expectations and difficulties that some teachers had found in implementing experimental activities during the Apprentice Project, as well as to overcome those difficulties. We tried to determine the potential that the interaction among university, public school, teachers, and pre-service teachers has on science/biology teacher education. Despite the difficulties, the collaborative work contributed to the education of teachers and pre-service teachers. Due to this research, teachers, pre-service teachers, and researchers had the possibility of expressing their conceptions and reflecting on the experimental activities in public schools.
\end{abstract}

Key words: Experimental activities. Teacher's education. Science education.

\footnotetext{
${ }^{1}$ Graduado em Ciências Biológicas, doutorando em Educação. Docente, Faculdade Aldeia de Carapucuiba, Fortaleza, CE, Brasil.<raphael.feitosa@ufc.br>

${ }^{2}$ Graduada em Ciências Biológicas, doutora em Educação. Docente, Departamento de Biologia, Centro de Ciências, Universidade Federal do Ceará (UFC). Fortaleza, CE, Brasil. <raquelcml@yahoo.com.br>

${ }^{3}$ Graduada em Ciências Biológicas, doutora (Nouveau Doctorat) em Biologia. Docente, Departamento de Bioquímica e Biologia Molecular, Centro de Ciências, UFC. Fortaleza, CE, Brasil. <pfreitas@ufc.br>
}

${ }^{1}$ Rua Padre Guerra, 361, apto. 104

Fortaleza, CE

$60.450-665$ 


\title{
Introdução
}

Analisando a literatura educacional sobre as propostas de mudança nas escolas, notamos, claramente, que elas são diversificadas, dão ênfase a aspectos distintos e a elementos do processo de ensino e aprendizagem, como professores, recursos, materiais didáticos e estratégias de ensino (CARVALHO; GIL-PÉREZ, 1995; AQUINO; MUSSI, 2001; SERRÃO, 2006). Porém, encontramos em comum, nas propostas de melhoria da Educação Brasileira, o fato de que elas abordam a formação inicial e continuada dos docentes.

Nesta perspectiva, muitos autores estão em consonância em afirmar a importância da experiência e da prática profissional para o desenvolvimento de bons professores (TARDIF, 2006; TERRIEN, 1997; SERRÃO, 2006). Concordamos com Therrien (1997), quando o autor ressalta a importância dos saberes experienciais - fruto da vivência e da prática profissional dos atores sociais - para o trabalho docente:

\begin{abstract}
Nossas investigações se juntaram então aos estudos voltados para os saberes mobilizados nas práticas educativas, em particular os saberes da ação, do saber-fazer, da experiência, como resultantes da transformação, na práxis, dos diversos saberes instituídos (curriculares, disciplinares e de formação profissional), bem como dos saberes da prática social e da cultura dos educadores. Nossas pesquisas anteriores revelavam que pelo ângulo da experiência os saberes escolares são retraduzidos, transformados e incorporados pelos docentes nas suas práticas quotidianas, integrando-se à sua identidade e constituindo-se elementos fundantes da condução de sua ação educativa, de seus julgamentos e de suas decisões pedagógicas. (THERRIEN, 1997, p. 12)
\end{abstract}

Apesar de numerosos estudos se debruçarem sobre o tema da formação do educador, ainda persiste o descontentamento e a crítica dos docentes em relação à inadequação e à dissociação entre sua formação e as exigências da prática cotidiana da sala de aula. Por isso, a importância de se estudarem os aspectos que se relacionem à formação inicial e continuada de professores.

A pesquisa em educação no Brasil tende a gerar, entre os professores da escola Básica, o sentimento de que os pesquisadores, quando vão às escolas com seus importantes projetos, limitam-se a utilizá-las - e aos alunos - simplesmente com fonte de dados de pesquisa. É preciso que os professores e alunos das escolas pesquisadas tenham ganhos reais com os projetos executados (FREIRE, 2005). Por essa razão, decidimos pela elaboração de um projeto de pesquisa, ensino e extensão que realiza atividades experimentais em Biologia, tendo em consideração a troca de experiências e a oportunidade de engrandecimento de todos os participantes do projeto.

O "Projeto Aprendiz" é o fruto de tal proposta, que foi elaborada a partir da iniciativa do Programa de Educação Tutorial (PET/Biologia-MEC/SESu/DEPEM) da UFC, observando a importância de se desenvolverem atividades experimentais nas escolas públicas. As ações de destaque desse projeto são o incentivo à reativação de laboratórios de aulas práticas de Ciências em escolas públicas de Fortaleza e a criação de uma apostila, que contém experimentos que auxiliarão as aulas práticas. 
Esta ação foi efetivada por meio da elaboração conjunta de aulas práticas pelos participantes do projeto, a saber: professores das escolas da rede pública de ensino, 12 bolsistas ${ }^{4}$ do programa PET e um professor universitário do mesmo curso, o qual agiu como tutor que coordenou as ações do grupo.

Nas atividades experimentais, buscou-se desenvolver uma metodologia criativa e inovadora, que valorizasse o raciocínio lógico e a capacidade crítica de estudantes e professores de Ciências, com ênfase para a disciplina de Biologia no Ensino Médio. Assim, pretendíamos ampliar os laços entre Universidade e Escolas de Ensino Básico, por meio de uma articulação colaborativa, buscando efetivar a formação inicial dos graduandos e a continuada dos docentes que já exerciam a profissão.

Até o ano de 2005, o "Projeto Aprendiz" apenas revitalizava ${ }^{5}$ laboratórios, ou seja, era uma atividade de extensão. A partir de 2006, foi decidido que, além de extensão, o projeto também se tornaria uma atividade de pesquisa em grupo, visando atender algumas indagações surgidas durante as atividades nas escolas públicas.

Concordamos com autores que afirmam que, para os professores em processo de formação inicial (alunos de cursos de graduação), bem como para aqueles que já exercem a profissão, o contato com o planejamento conjunto e a prática reflexiva parece ser um fator positivo ao desenvolvimento de atividades dos futuros docentes (CARVALHO et al., 2003; LIMA, 2001).

Assim, este estudo enfoca a experiência subjacente aos saberes ${ }^{6}$, fazeres, e o trabalho de professores de duas escolas públicas de Ensino Médio em seu cotidiano escolar. Nossa experiência se sucedeu a partir da articulação entre a formação inicial de alunos de graduação e a formação continuada de professores em pleno exercício da profissão.

O caminho trilhado para a implementação do "Projeto Aprendiz" seguiu quatro passos básicos. Inicialmente, tivemos uma aproximação inicial com os professores das escolas participantes, buscando compreender o contexto escolar que emergia dessas instituições, bem como conhecer sua estrutura física. Em seguida, iniciamos, dialogicamente, um trabalho visando adequar os experimentos aos conteúdos curriculares de cada docente. Isso, pois, era nossa intenção: apoiar o planejamento anual feito pelos professores. Assim, as atividades experimentais propostas no projeto deveriam auxiliá-los na abordagem dos seus conteúdos curriculares, visando à construção coletiva de saberes parceiros. Desta forma, buscamos ouvir e partilhar, dialogicamente, as suas narrativas sobre os saberes e fazeres desenvolvidos na tessitura do coletivo escolar, por meio de atividades experimentais de Biologia que foram planejadas em conjunto.

O terceiro momento foi o planejamento conjunto das atividades no laboratório didático de Biologia/Ciências. Anteriormente à aplicação de cada atividade experimental nas escolas, o

\footnotetext{
${ }^{4}$ Esses serão chamados aqui de "petianos" (sete mulheres e cinco homens), os quais eram alunos do curso de Ciências Biológicas (entre o terceiro e o oitavo semestres do mesmo).

${ }^{5}$ Revitalizar significa, neste trabalho, retomar as atividades experimentais, com aulas práticas nas escolas. Isto porque as escolas participantes do Projeto Aprendiz possuíam laboratórios de Ciências, porém os docentes não ministravam aulas práticas nesses espaços de transformação dos saberes.

6 "Saberes" são abordados nesta obra de forma ampla, como um conjunto de conhecimentos, competências e habilidades dos grupos informantes.
} 
experimento era discutido e realizado com o professor e com os petianos. Os monitores da escola, alunos voluntários selecionados para auxiliar nas aulas práticas, também eram convidados a participarem desse momento. Foram marcados encontros que, geralmente, ocorriam nos horários de planejamento dos professores, ou em outros horários em que os mesmos estivessem disponíveis. Nesse momento, era analisada a viabilidade do experimento, seu tempo de duração e quais os materiais que haviam de ser providenciados. O próprio professor organizava e efetuava o experimento, sendo orientado, quando necessário, pelos petianos. Dessa maneira, o próprio profissional tinha a oportunidade de vivenciar a prática, o que era fundamental, sobretudo para aqueles que não haviam tido muitas experiências com esse tipo de aula durante a sua formação.

Finalmente, o quarto passo percorrido foi a avaliação permanente das atividades desenvolvidas nas escolas. Para tanto, o grupo participante, incluindo-se "petianos", docentes e tutor, reunia-se após os experimentos e dialogava sobre suas ações.

A fim de orientar nossa proposta, essa perspectiva de pesquisa-ação colaborativa tomou como base alguns pressupostos. Concordamos com Tardif (2006) e Therrien (1997) ao afirmarem que o trabalho docente é uma atividade de interações humanas, complexa, contextualizada e histórica. E em seu cotidiano, o docente transforma e (re)constrói os saberes escolares, baseando-se, inclusive, na sua vivência pessoal. Desta forma, entendemos que:

De fato se admitirmos que o movimento de profissionalização é, em grande parte, uma tentativa de renovar os fundamentos epistemológicos do ofício de professor, então devemos extrair daí elementos que nos permitam entrar num processo reflexivo e crítico a respeito de nossa próprias práticas como formadores e como pesquisadores. (TARDIF, 2006, p. 254)

Concluir que os docentes produzem saberes específicos no decorrer de sua práxis educativa, não sendo apenas mediadores ou meros repassadores de saberes produzidos por outros, abre o espaço para o debate sobre a identidade profissional destes atores sociais. A observação empírica da ação docente colocou, para além da natureza social do exercício da profissão, questões de teor epistemológico quanto à natureza, origem e fundamentos dos saberes à base da prática docente. (THERRIEN, 1997, p. 11)

Segundo estes autores, a formação do professorado, tanto a inicial quanto a continuada, deve estar enriquecida com as relações humanas, tecidas através de saberes parceiros, que criem condições para a re(construção) dos saberes. Desta forma, será possível o desenvolvimento de professores que realizem atividades práticas, nas quais seus aprendizes passarão a ter um papel ativo no processo de ensino-aprendizagem.

Assim, buscamos mostrar que os docentes constroem a sua própria profissão. Esta forma de pensar foi referendada por Tardif (2006), ao tratar este pensamento de epistemologia da prática profissional:

Chamamos de epistemologia da prática profissional o estudo do conjunto de saberes utilizados realmente pelos profissionais em seu espaço 
"Projeto Aprendiz": interação universidade-escola ...

de trabalho cotidiano para desempenhar todas as suas tarefas. (TARDIF, 2006, p. 255, grifo dos autores)

A finalidade de uma epistemologia da prática profissional é revelar esses saberes, compreender como são integrados concretamente nas tarefas dos profissionais e como estes os incorporam, produzem, utilizam, aplicam e transformam em função dos limites e dos recursos inerentes às suas atividades de trabalho. Ela também visa compreender a natureza desses saberes, assim como o papel que desempenham tanto no processo de trabalho docente quanto em relação à identidade profissional dos professores. (TARDIF, 2006, p. 256)

Diante do exposto anteriormente, o objetivo deste trabalho é investigar as dificuldades dos docentes para a implementação de atividades experimentais, durante a aplicação do "Projeto Aprendiz", e, sobretudo, a superação destes obstáculos. Ademais, buscamos compreender a contribuição do referido projeto para a formação inicial dos graduandos de Ciências Biológicas que atuaram no projeto.

\section{A importância das atividades práticas no Ensino de Ciências}

A análise do papel das atividades experimentais desenvolvidas amplamente nas últimas décadas revela que há uma variedade significativa de possibilidades e tendências de uso dessa estratégia de Ensino de Ciências (ARRUDA; LABURÚ, 1998; ARAÚJO; ABIB, 2003; FRANCALANZA; AMARAL; GOUVEIA, 1987; KRASILCHIK, 2005; LABURÚ; BARROS; KANBACH, 2007; LORETO; SEPEL, 2003; ROSA, 2003). Para alguns pesquisadores, parece haver uma unanimidade, pelo menos no plano dos conceitos, entre educadores para as Ciências e a Matemática, quanto à necessidade de se adotarem métodos de aprendizado ativos e interativos (BRASIL, 1999).

Desde a década de 1930, as propostas de reformas educacionais no Ensino de Ciências visam mudanças na forma do processo de ensino-aprendizagem, como, por exemplo, a substituição dos métodos expositivos pelos chamados métodos ativos, dentre os quais se sobreleva o laboratório. O laboratório pode ser definido como uma dependência adaptada para o trabalho prático, devendo ter condições especiais relativas ao trabalho experimental (KRASILCHIK, 1987).

Já no início do século XXI, segundo levantamento realizado por Krasilchik (2005), destacam-se, na literatura, as seguintes funções das aulas práticas:

Despertar e manter o interesse dos alunos; envolver os estudantes em investigações científicas; desenvolver a capacidade de resolver problemas; compreender conceitos básicos [...] formular, elaborar métodos para investigar e resolver problemas individualmente ou em grupo; analisar cuidadosamente, com companheiros e professores, os resultados e significados de pesquisas, voltando a investigar quando ocorrem eventuais contradições conceituais; compreender as limitações do uso 
de um pequeno número de observações para gerar conhecimento científico e compreender as funções que exercem na ciência, como são elaboradas e testadas as hipóteses e teorias; permitem que os alunos tenham contado direto com os fenômenos manipulando os materiais e equipamentos e observando organismos. (KRASILCHIK, 2005, p. 85)

Para o aprendizado científico, matemático e tecnológico, a experimentação, seja ela de demonstração, seja de observação e manipulação de situações e equipamentos do cotidiano do aluno e, até mesmo, a laboratorial, é distinta daquela conduzida para a investigação científica e é particularmente importante quando permite, ao estudante, diferentes e concomitantes formas de percepção qualitativa e quantitativa, de manuseio, observação, proposição de hipóteses, confronto, dúvida e de construção conceitual (BRASIL, 1999).

Vale ressaltar que, nas aulas com atividades experimentais, os alunos enfrentam resultados não previstos, cuja interpretação desafia sua imaginação e raciocínio. Nesse sentido, essas práticas podem gerar atividades que motivem os alunos, e, como isso, suscitar uma aprendizagem significativa (ROSA, 2003).

Em relação ao aspecto do processo de ensino-aprendizagem por experimentação, ressaltamos que cabe ao docente não apenas se preocupar com aspectos relacionados à experiência em si, mas também com as estratégias que favorecerão a apropriação dos conceitos e fenômenos abordados na atividade realizada. Para tanto, julga-se conveniente destacar, neste texto, como forma de fundamentar as concepções teórico-metodológicas dos professores investigados, as ideias decorrentes da psicologia cognitivista na perspectiva da teoria históricocultural, que apresenta uma identificação no trabalho (ALVES-FILHO, 2000; GASPAR; MONTEIRO, 2005). A relação entre aprendizado e desenvolvimento na perspectiva sociointeracionista, concebe que a escola tem a função de despertar os vários processos internos capazes de operar quando o aluno interage com outro aluno ou com o professor (ROSA, 2003). Isto facilita a internalização dos conceitos (LIMA; PAULINO-FILHO; NUÑEZ, 2004). A atividade experimental no laboratório didático é um momento ímpar nesse aspecto, o que torna relevante seu uso nas aulas de Biologia da escola Básica.

Se, por um lado, muito se discute sobre as potencialidades que o laboratório didático pode trazer para os alunos, por outro, é imperativo advertir que o professor necessita compreender pedagogicamente a proposta interacionista subjacente ao uso do laboratório didático. Desta forma, seria possível evitar a utilização das atividades experimentais que, em muitos casos, baseiam-se apenas em protocolos estruturados de tipo "receita de culinária" (HODSON, 1994), nas quais os alunos são levados a esse espaço com a função de seguir rigidamente o protocolo e confirmar a "teoria na prática". Tal perspectiva é restrita, pois não permite o diálogo entre os aprendizes, além de ressaltar uma visão conservadora das Ciências.

Ademais, existem algumas limitações para o uso do laboratório, como, por exemplo: $\mathrm{o}$ investimento financeiro na compra de material ${ }^{7}$ para as aulas, o tempo necessário à preparação das aulas e à sua concretização pelos estudantes (KRASILCHIK, 2005).

\footnotetext{
${ }^{7}$ Cabe ressaltar que, no "Projeto Aprendiz", utilizamos materiais alternativos (ROSA, 2003), ou seja, produtos de baixo custo, como fonte substituta para o uso das vidrarias e equipamentos sofisticados. 
"Projeto Aprendiz": interação universidade-escola ...

O uso do laboratório didático no Ensino de Ciências parece ser consensual entre os investigadores e, também, entre os professores que não refutam o uso de atividades experimentais no processo ensino-aprendizagem em Ciências. Se, por um lado, os docentes acenam para a importância do laboratório no ensino, por outro, de forma quase que paradoxal, não o utilizam (CARVALHO; GIL-PÉREZ, 1995).

Isso porque, segundo os professores, não há tempo suficiente para a preparação do material, falta-lhes segurança para controlar a classe, conhecimentos para organizar experiências, auxílio técnico para preparação e conservação de material e, também, não dispõem de equipamentos e instalações adequadas (CARVALHO et al., 2003; KRASILCHIK, 1987; LABURÚ; BARROS; KANBACH, 2007; POSSOBOM; OKADA; DINIZ, 2003).

Para ressaltar esta difícil inserção destas atividades práticas, como exposto acima, recente pesquisa, realizada em duas escolas públicas da cidade de Fortaleza, por Feitosa et al. (2007), mostrou que a grande maioria $(72,5 \%)$ dos alunos entrevistados não tem acesso a nenhum tipo de aula prática em sua escola.

Todavia, é cabível denotar que há possibilidade de se proferirem aulas de Ciências com o uso de atividades experimentais fora do laboratório didático, desde que os critérios de segurança e conforto sejam observados (LORETO; SEPEL, 2003). Todavia, considerando que esse espaço didático estava disponível para nossa utilização no projeto, decidimos que as atividades experimentais seriam desenvolvidas no mesmo.

\section{Formação continuada e inicial de professores de Biologia}

Vários trabalhos investigam o pensamento de professores de Ciências: suas ideias sobre a Ciência, o ensino e a aprendizagem, e mostram que estas concepções são acompanhadas de rotinas muito bem estabelecidas, estáveis e resistentes a mudanças (ROSA; SCHNETZLER, 2003). Partimos da premissa de que tais concepções influem nas ideias que se constroem no grupo sobre os níveis de investigação educativa possíveis de se desenvolver a partir da interação entre professores da escola e assessor externo. Entendemos que as concepções de ensino são um reflexo de outras concepções que fazem parte do ser profissional docente (eg. formação profissional, saberes disciplinares e curriculares, concepções adquiridas através da experiência docente). De acordo com esta orientação, as atividades experimentais de Biologia podem ser um referencial satisfatório para a formação do interesse no aprendiz.

Buscando sanar os problemas da formação docente, algumas iniciativas de formação continuada de professores restringiram-se à participação de educadores em situações formativas pontuais, como cursos, palestras (AQUINO; MUSSI, 2001). No geral, estes se caracterizam por um conjunto de ações descontinuadas, parceladas, sem conexão entre si, e, ainda, com grande rotatividade de pessoas, condição esta que privilegia o caráter imediatista de seus objetivos.

Segundo Vianna e Carvalho (2000), a formação continuada dos docentes deve levar em consideração um modelo que se baseie numa reflexão do professorado sobre a sua prática docente, que lhe permita repensar sua teoria implícita do ensino, os seus esquemas básicos de funcionamento e, consequentemente, as suas próprias atitudes (AQUINO; MUSSI, 2001; GARCIA, 1995; SCHÖN, 1995). Assim, é possível que o profissional aprenda a partir da análise e interpretação de sua própria prática docente. Desta feita, as atividades de formação 
continuada de docentes devem procurar a superação da racionalidade técnica (atitudes burocráticas que regem as instituições educacionais), buscando a racionalidade prática, que oferece os elementos para compreender que o que guiará a ação de investigação do professor é seu senso crítico e ético (SERRÃO, 2006). Portanto, para superarmos os obstáculos do cotidiano docente é de suma importância a união entre reflexão e ação como a força motriz capaz de transformar o mundo, ou seja, a práxis autêntica (FREIRE, 2005).

\section{Procedimentos metodológicos}

Privilegiamos, em nossa pesquisa, práticas de formação em serviço que, em sua proposta formal, estivessem referenciadas pelos discursos teóricos que concebem o professor como um profissional reflexivo (AQUINO; MUSSI, 2001; GARCIA, 1995; QUEIROZ, 2001; SCHÖN, 1995; SERRÃO, 2006), em contraposição às concepções que circunscreveram a prática docente apenas como um exercício técnico de saberes. Os professores têm, nesta visão privilegiada, de se assumirem como produtores críticos e reflexivos da sua profissão.

Optamos por desenvolver relações horizontais entre investigadores e docentes na perspectiva de uma pesquisa-ação colaborativa, de acordo com Pimenta (2005). A pesquisaação tem como característica básica o pressuposto de que os sujeitos participantes compõem um grupo com metas comuns, preocupados com um problema que emerge no contexto local no qual atuam seus atores sociais (BARBIER, 2002). Já a pesquisa colaborativa tem por objetivo criar, nas escolas, uma cultura de análise das ações institucionais que são realizadas, a fim de possibilitar que os seus docentes, auxiliados pelos professores das universidades, transformem suas práticas (PIMENTA, 2005).

Deixamos de lado as relações de dominação de conhecimento, nas quais os pesquisadores universitários são "detentores" do saber e os pesquisados recebedores de um "saber estático", para navegarmos no oceano dialógico, no qual o diálogo horizontal entre todos os participantes do projeto é a fonte primária para a ampliação do desenvolvimento mútuo de ambas as partes. Partimos da premissa de que "ninguém educa ninguém, ninguém educa a si mesmo, os homens se educam entre si, mediatizados pelo mundo" (FREIRE, 2005, p. 78).

Desta forma, o "Projeto Aprendiz" foi desenvolvido em duas escolas públicas da cidade de Fortaleza no ano de 2006, que serão intituladas, neste trabalho, de escola "A" (com um total de cinco professores de Biologia) e escola "B" (total de cinco professores de Biologia), das quais participaram dessa pesquisa-ação colaborativa, respectivamente, três e uma docentes das escolas mencionadas. Elas serão aqui identificadas como "1", "2", "3" (escola "A") e "4" (escola "B"). Estas docentes, todas mulheres, eram professoras do $1^{\circ}$ ano do Ensino Médio.

A escolha das escolas deveu-se aos seguintes fatores: a localização da escola na cidade de Fortaleza, ou seja, sua acessibilidade ao grupo PET Biologia, a presença de laboratório didático desativado, e a disponibilidade, por parte dos professores da escola, de colaborarem com os pesquisadores.

À medida que ocorriam as intervenções nas escolas, utilizamos algumas ferramentas para a coleta dos dados da pesquisa, como, por exemplo: observação participante e entrevistas não diretivas ${ }^{8}$ (SILVERMAN, 2009). Nas pesquisas de caráter qualitativo, como a pesquisa- 
"Projeto Aprendiz": interação universidade-escola ...

ação colaborativa, é conveniente se utilizarem várias ferramentas de coleta de informações. André (1995) sugere o emprego de diferentes métodos de coleta de dados, obtidos por intermédio de uma variedade de informantes, em uma diversidade de situações, e a subsequente triangulação das informações obtidas. A triangulação permite evitar ameaças à validade interna inerente à forma como os dados de uma investigação são recolhidos.

Durante o planejamento conjunto e a realização das atividades experimentais, fizemos observações buscando compreender a construção do conhecimento que porventura influenciaria as aulas práticas realizadas posteriormente. Observamos, também, as próprias atividades experimentais, a fim de perceber como elas ocorriam nas instituições.

Por fim, aplicamos entrevistas não diretivas com o objetivo de conhecer mais detalhadamente a formação profissional das docentes encarregadas de ministrar as aulas práticas. Ainda, entrevistamos os próprios "petianos", para compreendermos as dificuldades dos graduandos do curso de Ciências Biológicas, bem como os pontos positivos do desenvolvimento do "Projeto Aprendiz".

Ao todo, para a coleta dos dados que são apresentados neste texto, a pesquisa durou um período de oito meses, incluindo-se os quatro passos básicos anteriormente apresentados: contato inicial, adequação dos experimentos aos conteúdos curriculares da disciplina Biologia, planejamento/desenvolvimento das ações e avaliação permanente das atividades.

\section{Resultados e discussão}

\section{Considerações sobre as professoras compartes do projeto}

Nesta seção, discutiremos um pouco sobre as características dos docentes que participaram do "Projeto Aprendiz" (1), observando, em especial, a formação de origem dos mesmos. Em seguida, comentaremos sobre a vivência passada dos compartes a respeito de aulas envolvendo atividades experimentais (2), nas quais estes participaram e/ ou foram os protagonistas do trabalho docente, e, finalmente, a importância que os professores atribuem para as aulas com experimentos no Ensino Médio (3).

\section{Características dos docentes}

A professora "1" é graduada em licenciatura curta em Estudos Sociais e em Terapia Ocupacional, com pós-graduação em Psicopedagogia. "Sou professora há nove anos, e ensino nesta escola a seis".

"2" é formada em Fonoaudiologia. Porém, houve uma mudança ao longo de sua carreira profissional, vindo a se graduar em Licenciatura em Biologia: "Trabalhei em Fonoaudiologia, mas o mercado [de trabalho] é fechado e incerto. Assim en fiz, outra faculdade".

${ }^{8}$ Para a coleta de dados, utilizamos anotações em caderno de campo de acordo com André (1995). 
“3” é graduada em Agronomia e possui mestrado. Segundo ela:

"Fiz. licenciatura em Agronomia após o bacharelado, curso que atualmente está fechado. Com este curso eu posso ensinar Matemática, Química, Física e Biologia, as Ciências exatas. Fiz mestrado [...], e também fiz o curso de Licenciatura em Letras, mas queria ter feito Geografia. Atualmente en dou aula de Biologia aqui e em outra escola". (professora "3")

Já a professora "4" é formada em Licenciatura em Biologia.

Notamos que a grande maioria das professoras das escolas participantes possui uma formação na área das Ciências. Em especial, ressaltamos que apenas a professora "4" possui graduação em Biologia (Licenciatura), disciplina em que as atividades do "Projeto Aprendiz" foram desenvolvidas.

É interessante observar que as professoras de Biologia em questão, cuja área de formação é diferente das Ciências Biológicas, parecem depender muito dos saberes da experiência profissional, adquirida ao longo dos anos de magistério, para realizar o trabalho docente cotidiano, como notamos no relato de uma das professoras:

"Olha, faz. um tempo que eu num dô (sic)" isso [atividades experimentais]. Mas no ano passado, eu pedi ajuda pros outros professores e eles me deram uns textos disso. Mas a gente aprende dar essas aulas mesmo é fazendo, ne’". (professora "2")

Percebemos que essa professora relata que o aprendizado da profissão ocorre através da experiência. Sobre esse tema, concordamos com Therrien (1997), ao afirmar sobre a estima da vivência social e cultural dos docentes. $\mathrm{O}$ autor alega que os docentes, como atores sociais da educação, "devem gerenciar ao mesmo tempo muitas lógicas e racionalidades de ação num sistema social marcado por diversas lógicas, o que contribui para uma melhor compreensão da natureza do saber de experiência docente" (THERRIEN, 1997, p. 16).

\section{Vivência com atividades experimentais}

As professoras "1", "2" e "4" tiveram poucas atividades práticas e estas foram concentradas em uma pequena parcela da formação acadêmica. Como relata "2": "Não tive muitas aulas práticas. Só que quando eu tive, as práticas foram muitas em pouco tempo".

Apenas " 3 " afirmou ter mais experiências desta natureza:

"Eu tive aulas de laboratório no Departamento de Zootecnia. Toda parte do reino animal está vinculada a ela. Anatomia dos Animais Domésticos, Exterior e

\footnotetext{
${ }^{9}$ As marcas de oralidade foram mantidas para preservar a veracidade e a intencionalidade dos discursos de todas as informantes desta pesquisa.
} 
"Projeto Aprendiz": interação universidade-escola ...

Raças, Nutrição de Animais Domésticos, Forragens e Plantas Nativas, Caprinos e Ovinos, Ruminantes, Não-Ruminantes, Melhoramento Animal. Esta última não era laboratório, era aula prática. Faziamos sexagem, castração entre outras. Era aula de campo, e aula de campo não é aula de laboratório, é aula prática." (professora " 3 ")

De acordo com as afirmações das próprias docentes, vistas acima, notamos claramente que, durante a formação inicial e/ou continuada, estas professoras não tiveram oportunidade de conviver com atividades práticas. Talvez, por isso, emerge a mesma tendência entre as professoras: a de recorrer aos saberes da experiência como elementos fundantes de sua prática docente cotidiana (como no relato da professora "2" no tópico anterior).

\title{
3 Importância que as professoras atribuem às atividades experimentais
}

A maioria das entrevistadas acha que é de suma importância a experimentação no Ensino de Ciências. Para a docente "1":

\begin{abstract}
"[As atividades experimentais] são importantíssimas, contanto que dentro de um cronograma bem elaborado e planejado. Dentro da minha realidade e o tempo de 55 min, pois considero curto, torna-se uma aula muito atropelada. Não vejo desvantagens, só se houver falhas no planejamento". (professora "2")
\end{abstract}

Já para a "4": "Eu acho super-importante! Fixa mais o conteúdo. E eles podem ver que é real. Não tá só no livro. Aliando ao cotidiano deles fixa 100\% da matéria”. Diante dessa afirmação, percebemos que essa docente parece conceber que a função das atividades experimentais é a de comprovar o que diz a teoria. Todavia, Krasilchik (2005) ressalta que essa concepção é reducionista, pois essa aplicação direta dos conhecimentos teóricos nos laboratórios de Ciências pode gerar um ensino descontextualizado. Os experimentos, muito além de apenas "fixar o conteúdo", podem proporcionar, aos alunos, a apropriação de um conhecimento mais próximo de situações cotidianas, identificadas com o contexto social e cultural do aluno.

Notamos, claramente, que as professoras "2" e " 3 " (ver item 2) possuem uma concepção diferente da literatura pedagógica sobre a modalidade didática de aulas práticas (KRASILCHIK, 2005; ROSA, 2003). Por exemplo, no discurso de "2":

"Eu faço a prática da vida (cotidiano). Por exemplo, eu mando eles olharem lipídios, carboidratos nos produtos do supermercado". "Na aula de minerais e água eu peço pra pesquisar muitos sais e fontes alimentares, a importância. Aí eu falo de nutrição... carência de sal ou excesso, gordos e magros, anabolizantes... Os alunos devem ser multiplicadores para familiares e amigos. Não é só pro vestibular ou concurso, é pra sua vida". (professora "2")

É pertinente investigar a importância dessa relação de conceitos para a atividade didática das professoras. Pelo que foi exposto no tópico anterior, a professora "3" parece considerar como aula prática somente as atividades em que ela observava alguma utilidade concreta para a prática do agrônomo no campo. Por sua vez, a "2" concebe "práticas" como 
sinônimo de "cotidiano". Seria interessante perceber, em uma pesquisa posterior, se esse conceito se estende à concepção do que deve ser exercitado em aula.

\section{Não-realização de atividades experimentais}

Se, de um lado, elas falam sobre a importância das práticas, por outro, não as realizam em suas escolas, segundo relato das próprias docentes.

Analisando as respostas das entrevistas, bem como as observações participantes que realizamos, dividimos os diversos motivos que as docentes relataram sobre a não-realização de atividades experimentais em três categorias principais: (1) Dificuldades durante a Formação Profissional (inicial e continuada) dos docentes, (2) Dificuldades relacionadas à Estrutura Física e Apoio Técnico, e (3) Outras dificuldades, que contemplam temas diversos.

\section{Dificuldades durante a formação profissional}

Inicialmente, percebemos a escassez de trabalho prático durante a graduação das professoras, pois, segundo relatos, a maioria delas afirmou que nunca ministrou aulas práticas para seus alunos. Este parece ser um dos fatores frenadores para a não-realização de atividades experimentais nas escolas, pois a maioria das docentes teve pouco contato com esse tipo de prática durante seus cursos de graduação. Porém, esse não foi o único ponto de dificuldade apontado pelas participantes.

Outro problema relacionado pela professora "2" é "associar a (aula) teórica com a prática. Acho que eu tenho um comodismo mesmo meu". Para a docente " 1 ", o empecilho apontado foi "o tempo de aula", pois algumas experiências mais elaboradas, as quais necessitam mais tempo de preparo e manipulação, serão prejudicadas em sua realização.

Ressalta-se o desconhecimento destas docentes em relação a medidas de segurança, materiais necessários e apropriados para a montagem de um laboratório didático para a Educação Básica. Não saber o que se deve comprar para compor um laboratório com o objetivo didático, muitas vezes, levava-nos a situações inusitadas, como a presença, no laboratório de Biologia de uma das escolas observadas, de uma autoclave, material que pode ser considerado como não essencial aos tipos de experimentos que se destinam a tal nível escolar. Ademais, alguns reagentes já estavam com o prazo de validade vencido, pelo abandono que sofreram tais laboratórios.

Todas estas afirmações sobre as dificuldades enfrentadas pelos docentes a respeito de suas experiências em atividades experimentais foram repetidas, num verdadeiro tom de consonância, entre os docentes participantes do projeto. Assim, este problemático quadro não parece ser exclusividade das escolas analisadas, e sim uma representação do que ocorre em diversas escolas da rede pública (CARVALHO et al., 2003; POSSOBOM; OKADA; DINIZ, 2003).

\section{Dificuldades relacionadas à estrutura física e apoio técnico}

A professora " 2 " afirma que a falta de apoio técnico contribui para a não-realização de atividades experimentais: "Eu preciso de uma pessoa [um técnico ou outro professor] para me ajudar no laboratório, pois tem que ajudar a lavar [os materiais usados nas aulas]". 
"Projeto Aprendiz": interação universidade-escola ...

Já segundo "3", "O laboratório é inoperante. Acho que ia ser bom se eles olbassem no microscópio. Precisa de mais microscópio. Aula prática num dá pra faz̨er, dá só demonstração". Ainda sobre este tema, a professora "4" relatou: "Eu uso lâminas no microscópio. Se der pra levar metade da turma eu levo, se não en levo o monitor [TV] e transparências pra sala. E devia ter mais microscópios". Semelhante aos resultados obtidos por Krasilchik (1987), e Feitosa et al. (2007), está claro que a falta de equipamentos para uso em laboratório é um fator frenador do processo de ensino-aprendizagem escolar.

Outra dificuldade apontada por todas as professoras entrevistadas é o tamanho das turmas, que têm, em média, 35 alunos em ambas as escolas. Segundo Krasilchik (2005), para a objetivação das metas a serem atingidas pelas aulas práticas, o tamanho ideal de um laboratório de Ciências, para uma turma de trinta alunos, deve ser de um total de $90 \mathrm{~m}^{2}$. Onde cada aluno carece dispor de um espaço de $3 \mathrm{~m}^{2}$ para suas atividades laboratoriais. Segundo "2", este é um grande empecilho à realização de práticas.

Ademais, o grande número de alunos por turma é um outro fator citado para a nãorealização de atividades experimentais (FEITOSA et al., 2007; KRASILCHIK, 1987). Este dado, aliado ao fato das pequenas dimensões dos laboratórios das escolas (em duas escolas com medidas de: $11 \mathrm{~m}$ x $8 \mathrm{~m}$ ), impossibilita a presença de um grande número de alunos. Vale ressaltar que o ambiente de uma das escolas analisadas ("C") possui uma bancada central fixa que impede o deslocamento e o mínimo de conforto dos alunos durante o trabalho prático.

Finalmente, é necessária a construção de mais pias nas escolas, pois existem duas nos laboratórios da escola " $\mathrm{A}$ " e "B" e apenas uma na escola "C", sendo necessário ter o mínimo de quatro para uma turma de trinta alunos, de acordo com Krasilchik (2005).

Estes resultados são semelhantes aos encontrados em diversas pesquisas sobre este tema (FEITOSA et al., 2007; KRASILCHIK, 1987). Destacamos, ainda, o trabalho de Laburú, Barros e Kanbach (2007), que mostra o fracasso da implementação das atividades experimentais realizadas em escolas.

\section{Outras dificuldades}

Ainda devido às condições precárias das escolas públicas brasileiras e, também, em decorrência dos baixos salários de professores e funcionários, ocorreu, logo no início do projeto, uma paralisação das atividades da escola pesquisada, em função de uma greve de professores no ano de 2006, durante a qual foram suspensas todas as aulas das duas escolas, inclusive as práticas que começavam a ser implantadas. Essa paralisação interrompeu as observações que estavam sendo realizadas e, consequentemente, prolongou o tempo necessário para a conclusão da elaboração do projeto e da apostila que se encontrava em construção.

Além disso, o fato de as professoras que participavam da pesquisa estarem, não raramente, afastadas, por licença médica, da escola e do projeto de implantação das aulas práticas pode indicar, em certos casos, um desinteresse e falta de empenho de sua parte em obter sucesso no desenvolvimento de atividades pedagógicas inovadoras na escola, como é o caso do "Projeto Aprendiz". Essa falta de interesse, segundo Carvalho e Gil-Pérez (1995), pode ser causada: pela precariedade na estrutura das escolas, pela desorganização, por salários indignos e, também, pelo não-entendimento da responsabilidade da profissão docente por parte de alguns profissionais. 
Segundo alguns pesquisadores (BRASIL, 1999; GIL-PÉREZ; GUZMÁN OZÁMIZ, 1993), é preciso que as escolas assumam, como parte regular da promoção da educação científico-tecnológica, a concepção e a condução de projetos de trabalho coletivo, interdisciplinares. Pode-se perceber, com base nos resultados encontrados nestas atividades do "Projeto Aprendiz", quão significativa teria de ser a reformulação de postura pedagógica na maioria de nossas escolas para que tal promoção ocorra.

\section{Superação das dificuldades}

Anteriormente à chegada do projeto, foi citado, por um dos coordenadores de uma das escolas estudadas, que atividades experimentais nunca tiveram grande repercussão na escola. Para ele, a falta de periodicidade dos experimentos faziam os mesmos serem usados uma vez ou outra, não assumindo um caráter de aula prática ligada ao conteúdo dado em sala de aula. Essa articulação entre os conteúdos curriculares e as práticas foi um dos objetivos do "Projeto Aprendiz".

O projeto foi muito bem recebido pelas duas escolas, sendo que um dos principais problemas enfrentados por todos que estavam participando foi a falta de um calendário escolar bem desenvolvido a ser seguido. Como o projeto foi apresentado momentos depois das atividades de planejamento e as aulas escolares do ano já terem sido estabelecidas, não estando entre elas contempladas atividades experimentais, podemos dizer que o encaixe destas no plano anual das escolas, já feito, foi de certa forma dificultado.

Seguindo as ideias de Carvalho et al., (2003) e Possobom, Okada e Diniz (2003), para superarmos a falta de materiais nos laboratórios das escolas, os participantes do projeto optaram por substituir vidrarias por materiais alternativos (por exemplo, trocar um béquer por um copo de vidro).

As aulas práticas foram realizadas nos próprios horários das aulas de Biologia e contavam com a metade da turma, a qual era dividida pela professora, devido ao fato de o espaço físico do laboratório não poder suportar todos os alunos de uma mesma turma.

Ligado a esse fato, tivemos de ultrapassar outra dificuldade: o que fazer com a outra metade da turma (aquela que não estava no laboratório)? Para superar esse desafio, juntamente com as coordenações das escolas, decidimos construir, durante o ano, diversas atividades com esses alunos, como, por exemplo: entrevistas, pesquisas e questionários sobre Biologia, além de leituras coletivas nas bibliotecas das escolas, entre outras formas criativas de superar este obstáculo. Essas ações tiveram como objetivo refletir com os alunos sobre os conteúdos curriculares de Biologia, em especial aqueles mais ligados às atividades experimentais desenvolvidas na escola durante esse período.

Vale ressaltar que, por iniciativa inteiramente própria, os docentes sentiram-se estimulados a desenvolverem atividades experimentais, com a vivência com o "Projeto Aprendiz". Por exemplo, a professora " 2 " ministrou uma aula prática sobre composição químicas dos alimentos e sua relação com as células. Ela utilizou materiais alternativos (papel de filtro, óleo, lâmpada aquecedora) e, junto com os discentes, observou que alguns alimentos, como a manteiga, possuem considerável quantidade de lipídeos, qualitativamente expostos no papel de filtro após a secagem em lâmpada aquecedora. 
"Projeto Aprendiz": interação universidade-escola ...

Para mudar o quadro atual do Ensino de Ciências, é preciso que haja uma interação participativa entre docentes e diretores nas escolas (CARVALHO; GIL-PÉREZ, 1995; ALVES-FILHO, 2000). Um exemplo desta participação ocorreu na escola "B", onde, depois do início das atividades do "Projeto Aprendiz", o corpo de diretores solicitou, junto à Secretaria de Educação do Estado, um professor de Laboratório, exclusivo para o trabalho com atividades experimentais nas diversas turmas de Ciências e Biologia da escola. Ainda hoje (2010), pode-se contar com a colaboração deste professor.

Porém, apesar das inúmeras dificuldades apontadas nos parágrafos acima, consideramos que é possível a superação de tais dificuldades. Nos subitens abaixo, mostraremos alguns dos avanços que o "Projeto Aprendiz" teve durante sua aplicação.

\section{As aulas de laboratório realizadas}

Durante o ano de 2006, as professoras participantes do "Projeto Aprendiz" realizaram um total de 12 aulas de laboratório. Destacamos, em conjunto com todas as professoras e petianos envolvidos, que os assuntos a serem abordados nas atividades deveriam ser aqueles que fossem ao encontro do planejamento curricular das professoras para o $1^{\circ}$ ano do Ensino Médio. Desta feita, os seguintes temas foram escolhidos em comum pelo grupo: vidrarias e materiais de laboratório, noções de microscopia, observação da atividade da enzima catalase em materiais biológicos, e composição química dos alimentos. Ressaltamos que estas atividades foram realizadas pelas professoras com o auxílio de alunos monitores da própria escola. Os petianos e o professor tutor fizeram uso da observação participante durante estas aulas.

\section{Elaboração de uma apostila}

Aproveitando o trabalho realizado durante estas atividades nas escolas, o grupo envolvido no "Projeto Aprendiz" decidiu por unir as experiências de laboratório utilizadas durante o projeto. Assim, como um outro fruto deste trabalho no projeto, o grupo PET-Biologia elaborou uma apostila contendo as práticas desenvolvidas nesse período. Ademais, a mesma inclui questionamentos sobre as atividades experimentais e anexos explicativos sobre temas variados de Biologia para uso dos professores. Esse material traz uma problematização dos experimentos, uma contextualização da temática e sua articulação com os conteúdos curriculares específicos da disciplina de Biologia. Com isso, queríamos evitar que as atividades laboratoriais utilizadas no projeto fossem baseadas em protocolos de tipo "receita de culinária".

A apostila contém, ao todo, nove experimentos (conhecendo o laboratório e seus instrumentos; microscopia: a visão do "invisível"; osmose através de ovos "pelados"; extração de DNA de banana; onde está o amido?; atividade da enzima catalase; o poder redutor da vitamina C; fermentação; percebendo a fotossíntese), e seus respectivos anexos, sendo que cada anexo apresenta uma discussão mais detalhada do experimento e respostas aos questionamentos.

\section{Aprendizado dos petianos}

Segundo o relato dos petianos participantes do "Projeto Aprendiz", este foi uma importante oportunidade para interagirem com a realidade das escolas da cidade de Fortaleza. Oportunidade esta, marcada pelo desenvolvimento da noção de importância de atividades experimentais no Ensino da Biologia. Como demonstra este relato de um petiano: 
"Eu acredito que algo o colégio deve ter recebido de positivo dessa história [do projeto]. E acredito que os professores tiveram a oportunidade de compreender a verdadeira importância das aulas práticas no campo da Biologia". (petiano "1")

Outros petianos afirmaram que a experiência com o projeto trouxe bons frutos para sua formação inicial, como, por exemplo, a aproximação dos graduandos com as escolas públicas de Ensino Básico:

"Foi possivel analisar o comportamento de alunos e professores no ambiente da sala de aula, entender um pouco mais do funcionamento da escola e, sobretudo, observar as dificuldades enfrentadas no ensino público". (petiano " 3 ")

"No total, o projeto se mostrou importante por eu ter tido contato com um ambiente que pode ser o de trabalbo no futuro". (petiano "2")

É oportuno ressaltar que, no relato do petiano “2”, percebemos que, aparentemente, ele julga que se tornar um professor de Ensino Básico é apenas uma possibilidade "de trabalho no futuro" ${ }^{10}$.

Outros relatos demonstraram que, na universidade, são raras as ocasiões onde pode haver o fim da dicotomia teoria-prática, sendo o referido projeto uma atividade que alia ensino, pesquisa e extensão, tornando possível desobscurecer o papel da formação continuada de professores na área das Ciências.

Estas afirmações vão ao encontro das pesquisas realizadas por Lima (2001) e por Carvalho et al. (2003), as quais afirmam que o contato entre graduandos e professores de escolas de nível Fundamental e Médio é positivo para o desenvolvimento profissional dos futuros docentes em formação inicial.

Já outros petianos falaram que esta experiência trouxe a oportunidade de se resolverem diversos problemas, como, por exemplo, na comunicação e no relacionamento entre as pessoas participantes do projeto.

Finalmente, um integrante do grupo afirmou que, ao se deparar com a realidade dos docentes do Ensino Médio, notou que eles não podem planejar as aulas adequadamente, pois têm de trabalhar em diversas escolas para garantirem um salário digno. Afirmação essa que se solidariza com as precárias condições de trabalho e de remuneração às quais os professores estão submetidos (KRASILCHIK, 1987).

\footnotetext{
${ }^{10}$ Aqui, cabe denotar que o curso de Ciências Biológicas possuía, naquela época, um acesso único ao curso, através de exame vestibular, tanto para as modalidades de Licenciatura quanto Bacharelado. E o graduando podia optar, durante sua formação, por concluir uma ou ambas as modalidades. Daí o motivo de alguns alunos do curso ainda não saberem se iriam trabalhar como professores licenciados.
} 
"Projeto Aprendiz": interação universidade-escola ...

\section{Considerações finais}

Embora a importância das atividades experimentais tenha sido amplamente reconhecida pelos professores participantes do "Projeto Aprendiz", na realidade, elas formam uma parcela muito pequena da disciplina de Biologia no Ensino Médio.

Diante das afirmações dos professores, existem muitas dificuldades para a não- realização de atividades práticas no laboratório didático. Segundo os mesmos: não há tempo suficiente para a preparação do material, falta-lhes segurança para controlar a classe, conhecimentos para organizar experiências, auxílio técnico para reparação e conservação de material e, também, não dispõem de equipamentos e instalações adequadas. Estes resultados são semelhantes aos relatos encontrados na literatura do Ensino em Ciências (CARVALHO et al., 2003; KRASILCHIK, 1987; LABURÚ; BARROS; KANBACH, 2007; POSSOBOM; OKADA; DINIZ, 2003). No entanto, com o esforço dos participantes do "Projeto Aprendiz", foi possível a superação destas barreiras e a implementação de atividades experimentais na disciplina de Biologia no Ensino Médio, além da organização de uma apostila com os experimentos realizados nesse período. Destarte, é cabível destacar que o trabalho conjunto entre os participantes do projeto (graduandos, professores e tutor) nessas escolas perdura até os dias de hoje (2011).

O trabalho conjunto de professores em exercício e futuros docentes trouxe contribuição para formação de ambos. Os professores tiveram oportunidade de rever conceitos, construir novos conhecimentos e utilizar outra estratégia de ensino, no caso, as atividades experimentais. Por sua vez, segundo os relatos dos petianos, os licenciandos puderam se aproximar da realidade das escolas públicas e perceber dificuldades para a realização de propostas inovadoras, diferentes das tradicionalmente desenvolvidas, compreendendo o desafio de transformar em realidade o que foi planejado, além de poder interagirem com alunos, gestores e demais professores nas escolas. Nessa perspectiva, consideramos que o contato com as ações desenvolvidas em conjunto (planejamento, materialização e avaliação das ações do projeto) e a prática reflexiva oportunizada pelo projeto foram positivas à formação dos futuros Biólogos.

Com essa pesquisa-ação colaborativa, professores, licenciandos e pesquisadores tiveram a possibilidade de expressarem suas concepções e refletirem sobre a realização de atividades práticas nas escolas. Todavia, é importante realizar novas investigações a respeito dos saberes reconstruídos pelos docentes que participaram do projeto, durante o processo de formação continuada. Em especial, é relevante pesquisar se houve mudanças institucionais e/ ou subjetivas potencializadas (ou não) pelas vivências dos docentes com o projeto.

Os resultados obtidos no "Projeto Aprendiz", no que se refere aos aspectos de formação inicial e continuada de professores de Ciências, foram animadores. Porém, vale ressaltar que iniciativas como esta, apesar de extremamente proveitosas, não devem ser pontuais, carecem de continuidade e necessitam estar salvaguardadas por políticas públicas de formação docente. 
Feitosa, R. A.; Leite, R. C. M.; Freitas, A. L. P.

\section{Referências}

ALVES-FILHO, J. P. Regras da transposição didática aplicadas ao laboratório didático.

Caderno Catarinense de Ensino de Física, Florianópolis, v. 17, n. 2, p. 174-188, 2000.

ANDRÉ, M. E. D. A. Etnografia da prática escolar. Campinas: Papirus, 1995.

AQUINO, J. G.; MUSSI, M. C. As vicissitudes da formação docente em serviço: a proposta reflexiva em debate. Educação e Pesquisa, São Paulo, v. 27, n. 2, p. 211-227, 2001.

ARAÚJO, M. S. T.; ABIB, M. L. V. S. Atividades experimentais no ensino de física: diferentes enfoques, diferentes finalidades. Revista Brasileira de Ensino de Física, Porto Alegre, v. 25, n. 2, p. 176-194, 2003.

ARRUDA, S. M.; LABURÚ, C. E. Considerações sobre a função do experimento no ensino de ciências. In: NARDI, R. (Org.). Questões atuais no ensino de ciências. São Paulo: Escrituras, 1998. p. 53-60.

BARBIER, R. A pesquisa-ação. Brasília: Liber, 2002.

BRASIL. Ministério da Educação e do Desporto. Secretaria de Educação Fundamental. Parâmetros curriculares nacionais: Ensino Médio. Brasília: MEC, 1999.

CARVALHO, A. M. P.; GIL-PÉREZ, D. Formação de professores de ciências: tendências e inovações. 2. ed. São Paulo: Cortez, 1995.

CARVALHO, W. L. P. et al. O laboratório didático e o desenvolvimento do conhecimento pedagógico do conteúdo de professores de química. In: GARCIA, W. G.; GUEDES, A. M. (Org.). Núcleos de ensino. São Paulo: Unesp, Pró-Reitoria de Graduação, 2003. p. 306-317. Disponível em: <www.unesp.br/prograd/nucleo2003/index2002.php>. Acesso em: 1 ago. 2007.

FEITOSA, R. A. et al. "Projeto Aprendiz": concepções e dificuldades de professores de Biologia a respeito de atividades práticas. In: ENCONTRO NACIONAL DE ENSINO DE BIOLOGIA, 2.; ENCONTRO REGIONAL DE ENSINO DE BIOLOGIA, 1., 2007, Uberlândia. Anais... Uberlândia: Ed. da UFU, 2007. 1 cd-rom.

FRANCALANZA, H.; AMARAL, I. A.; GOUVEIA, M. S. F. O ensino de ciências no Primeiro Grau. São Paulo: Atual, 1987.

FREIRE, P. Pedagogia do oprimido. 46. ed. Rio de Janeiro: Paz e Terra, 2005.

GARCIA, C. M. A formação de professores: novas perspectivas baseadas na investigação sobre o pensamento do professor. In: NÓVOA, A. (Org.). Os professores e a sua formação. 2. ed. Lisboa: Nova Enciclopédia, 1995. p. 51-76.

GASPAR, A.; MONTEIRO, I. C. C. Atividades experimentais de demonstrações em sala de aula: uma análise segundo o referencial de teoria de Vigotski. Investigações em Ensino de Ciências, Porto Alegre, v. 10, n. 2, p. 227-254, 2005. 
"Projeto Aprendiz": interação universidade-escola ...

GIL-PÉREZ, D.; GUZMÁN OZÁMIZ, M. Enseñanza de las ciencias y la matemática: tendencias e innovaciones. [S.l.]: Organización de Estados Iberoamericanos para la Educacion, la Ciência y la Cultura, 1993. Disponível em: < http://www.oei.es/oeivirt/ ciencias.pdf>. Acesso em: 24 maio 2007.

HODSON, D. Hacia un enfoque más crítico del trabajo de laboratorio. Enseñanza de las Ciencias, Barcelona, v. 12, n. 3, p. 299-313, 1994.

KRASILCHIK, M. O professor e o currículo das ciências. São Paulo: EDUSP, 1987. Prática de ensino de biologia. São Paulo: EDUSP, 2005.

LABURÚ, C. E.; BARROS, M. A.; KANBACH, B. G. A relação com o saber profissional do professor de física e o fracasso da implementação de atividades experimentais no ensino médio. Investigações em Ensino de Ciências, Porto Alegre, v. 12, n. 3, p. 305-320, 2007.

LIMA, A. A.; PAULINO-FILHO, J.; NUÑEZ, I. B. O construtivismo no ensino de ciências da natureza e da matemática. In: NUÑEZ, I. B.; RAMALHO, B. L. (Orgs.). Fundamentos do ensino-aprendizagem das ciências naturais e da matemática: o novo Ensino Médio. Porto Alegre: Sulina, 2004. p. 84-101.

LIMA, M. S. L. Estágio supervisionado enquanto mediação entre a formação inicial do professor e a formação contínua. In: . (Org.). A hora da prática: reflexões sobre o estágio supervisionado e ação docente. Fortaleza: Edições Demócrito Rocha, 2001. p. 46-63.

LORETO, E. L. S.; SEPEL, L. M. N. Atividades experimentais e didáticas de biologia molecular e celular. 2. ed. São Paulo: SBG, 2003.

MIRANDA ARROYO, J. C. M. El aprendizaje escolar y la metáfora de la construcción. Revista Iberoamericana de Educación, Madrid, 2004. Disponível em: <http:// www.rieoei.org/deloslectores/630Miranda.PDF>. Acesso em: 24 maio 2007.

PIMENTA, S. G. Pesquisa-ação crítico-colaborativa: construindo seu significado a partir de experiências com a formação docente. Educação e Pesquisa, São Paulo, v. 31, n. 3, p. 521-539, 2005.

POSSOBOM, C. C. F.; OKADA, F. K.; DINIZ, R. E. S. Atividades práticas de laboratório no ensino de biologia e ciências: relato de uma experiência. In: GARCIA, W. G.; GUEDES, A. M. (Orgs.). Núcleos de ensino. São Paulo: Unesp, Pró-Reitoria de Graduação, 2003. p. 113-123. Disponível em: <www.unesp.br/prograd/nucleo2003/index2002.php>. Acesso em: 1 ago. 2007.

QUEIROZ, G. R. P. C. Processos de formação de professores artistas-reflexivos de Física. Educação \& Sociedade, Campinas, v. 22, n. 74, p. 97-119, 2001.

ROSA, M. I. F. P. S.; SCHNETZLER, R. P. A investigação-ação na formação continuada de professores de Ciências. Ciência \& Educação, Bauru, v. 9, n. 1, p. 27-39, 2003.

ROSA, C. W. Concepções teórico-metodológicas no laboratório didático de física na Universidade de Passo Fundo. Ensaio, Belo Horizonte, v. 5, n. 2, p. 13-27, 2003. 
Feitosa, R. A.; Leite, R. C. M.; Freitas, A. L. P.

SCHÖN, D. Formar professores como profissionais reflexivos. In: NÓVOA, A. (Org.). Os professores e a sua formação. 2. ed. Lisboa: Nova Enciclopédia, 1995. p. 77-92.

SERRÃO, M. I. B. Superando a racionalidade técnica na formação: sonho de uma noite e verão. In: PIMENTA, S. G.; GHEDIN, E. (Orgs.). Professor reflexivo no Brasil: gênese e crítica de um conceito. 4. ed. São Paulo: Cortez, 2006. p. 151-162.

SILVERMAN, D. Interpretação de dados qualitativos: métodos para análise de entrevistas, textos e interações. Porto Alegre: Artmed, 2009.

TARDIF, M. Saberes docentes e formação profissional. 6. ed. Petrópolis: Vozes, 2006.

THERRIEN, J. Saber da experiência e competência profissional: como os docentes produzem sua profissão. Contexto e Educação, Ijuí, v. 12, n. 48, p. 7-36, 1997.

VIANNA, D. M.; CARVALHO, A. M. P. Formação permanente: a necessidade da interação entre a ciência dos cientistas e a ciência da sala de aula. Ciência $\boldsymbol{\&}$ Educação, Bauru, v. 6, n. 1, p. 31-42, 2000.

Artigo recebido em maio de 2010 e aceito em outubro de 2010. 